\title{
Influência da densidade de plantio no crescimento da linhaça marrom
}

\author{
Influence of planting density on growth of brown flaxseed
Eduardo de Rossi', Cleber Antonio Lindino², Reginaldo Ferreira Sanos ${ }^{3}$, Paulo André Cremonez ${ }^{4}$, Willian Cezar Nadaletti ${ }^{5}$, Pedro Henrique Maschio ${ }^{6}$, Kenia Gabriela Dos Santos ${ }^{7}$ \\ 'Mestrando em Engenharia de Energia na Agricultura, Universidade Estadual do Oeste do Paraná - Campus Cascavel/Paraná-Brasil \\ ${ }^{2}$ Doutor em Química, Universidade Estadual do Oeste do Paraná - Campus Cascavel/Paraná-Brasil \\ ${ }^{3}$ Doutor em Agronomia, Universidade Estadual do Oeste do Paraná - Campus Cascavel/Paraná-Brasil \\ ${ }_{4}^{4}$ Mestrando em Engenharia de Energia na Agricultura, Universidade Estadual do Oeste do Paraná - Campus Cascavel/Paraná-Brasil \\ ${ }^{5}$ Doutorando em Engenharia Ambiental, Universidade Federal de Santa Catarina - Florianópolis - SC- Brasil \\ ${ }^{6}$ Graduando em Engenharia Civil, Universidade Paranaense - Cascavel - Paraná- Brasil \\ ${ }^{7}$ Mestranda em Engenharia de Energia na Agricultura, Universidade Estadual do Oeste do Paraná - Campus Cascavel/Paraná-Brasil
}

\begin{abstract}
Resumo
A linhaça pode ser consumida como alimento humano ou animal, além de ser utilizada para diversos outros fins, possui percentual de proteína em igual proporção de fibras e principalmente óleo, geralmente o produto de interesse nesta cultura, pode ser cultivada a linhaça dourada e marrom. O objetivo deste trabalho foi analisar a influência das densidades populacionais na cultura da linhaça marrom (Linum usitatissimum L.) utilizando-se o sistema de plantio em linha, estando distanciadas em 0,45 m. O experimento foi conduzido no campus da Universidade Estadual do Oeste do Paraná, ano de 2013, utilizando-se delineamento inteiramente casualizado com oito sistemas de plantio de adensamento: 67, 84, 99, 117, 137, 154, 172 e 190 plantas/m² com seis repetições, efetuou-se a colheita 130 dias após cultivo. O comportamento vegetativo foi avaliado seguindo-se as variáveis fenométricas altura de planta, diâmetro de caule, número de ramificações do caule, massa fresca e seca da parte aérea da planta, número de cápsulas, massa fresca e seca das sementes. Avaliando-se a os dados plotados na tabela gerada através da aplicação do teste de Tukey, não pode-se inferir os melhores adensamentos para plantio da linhaça marrom visando-se produtividade em grãos, apenas notou-se que adensamentos inferiores a 99 plantas $/ \mathrm{m}^{2}$ reduzem a produtividade em grãos de linhaça marrom.
\end{abstract}

Palavras-chaves: Concorrência; Variação populacional; Linum usitatissimum L..

\begin{abstract}
Flaxseed can be consumed as food or feed, besides being used for various other purposes, has a percentage of protein in equal proportion of fibers and mostly oil, usually the product of interest in culture can be grown brown and golden flaxseed. The objective of this study was to analyze the influence of population densities in the culture of brown flaxseed (Linum usitatissimum L.) using the online system of planting, being spaced at $0.45 \mathrm{~m}$. The experiment was conducted at the State University of West Paraná, year 2013 campus, using a completely randomized design with eight systems of planting density: 67, 84, 99, 117, 137, 154, 172 and 190 plants/m2 with six replicates, we performed 130 days after harvesting crops. The vegetative behavior was assessed following the variables fenometric plant height, stem diameter, number of branches of the stem, fresh and dry mass of the aerial part of the plant, number of capsules, fresh and dry seeds. Evaluating the data plotted in generated by applying the Tukey test, the table can not infer the best for high density planting of brown flaxseed aiming to yield grain, only it was noted that high density below 99 plants $/ \mathrm{m}^{2}$ reduce productivity in grain brown.
\end{abstract}

Keywords: Competition; Population variation; Linum usitatissimum L. 


\section{INTRODUÇÃO}

A linhaça (Linum usitatissimum L.) é uma planta anual pertencente da família das Lináceas, essa cultura é destinada a utilizações como alimentícia, fibras, tecidos e combustível (Morris e Vaisey-Genser, 2003). A linhaça é fonte de fibras alimentares, ácidos graxos, mucilagens e lignanas, caracterizando a sua utilização medicinal por conferir alguns efeitos fitoterápicos, mas também possui glicosídeos que pode ser tóxico e carcinogênico para humanos se ingerido em grandes quantidades (Alves, 2003; Gabiana, 2005; Schulz et al., 2001).

Linhaça é a semente de linho e foi introduzida no Brasil no século XVII em Santa Catarina (Marques, 2008; Marques, 2011). A linhaça originária da Ásia, mas seu consumo se difundiu mundialmente, sendo comum sua utilização na Europa e América do Norte (Bombo, 2006). A linhaça é uma das mais importantes plantas cultivadas mundialmente do ponto de vista de cobertura vegetal e teor de óleo.

Atualmente seu cultivo se concentra principalmente no Rio Grande do Sul, sendo que esta cultura possui necessidades de clima frio, com temperaturas próximas a $0^{\circ} \mathrm{C}$ até $-2^{\circ} \mathrm{C}$, para que ocorra a floração. O teor de óleo encontrado nas sementes encontra-se entre 38 e $48 \%$, esse óleo é destinado a indústrias para fabricação de tintas, plásticos de PVC, vernizes, e utilizado em produtos alimentares ou de higiene pessoal, sendo o restante em fibras e proteínas em igual proporção (Kouba, 2006; Oomah, 2001; Rabetafika, 2011; Soares et al., 2009).

Marques (2008) relata existir duas principais variedades de linhaça, a marrom e a dourada, sendo que estas não apresentam diferenças grandes quanto à proporção e composição química. Porém a linhaça dourada é considerada melhor adaptada aos climas frios, apresentando uma pequena quantidade a mais de proteína se comparada à linhaça marrom.

Seu plantio ocorre nos meses de maio e junho e a colheita entre outubro e dezembro. Segundo Vieira et al. (2012), a linhaça não exige grandes tratos culturais, indicado para a rotação de culturas, recuperando terras cansadas e evitando o desgaste e a erosão do solo, além de aproveitar a adubação residual do milho e da soja atualmente cerca de $40 \%$ de toda linhaça do mundo é produzido pelo Canadá (Oomah, 2001; Trucom, 2006).

Tomassoni et al. (2013), vários fatores podem em sinergia afetar o potencial de produção da linhaça, sendo destacado ente estes o processo de semeadura, a escolha adequada do arranjo de plantas, dentre eles em linha e a lanço, a densidade também pode refletir no aumento ou diminuição da interceptação e o uso da radiação solar perante Argenta et al. (2001).

Em nível mundial, a população de plantas recomendadas para a cultura da linhaça varia de 250 a 400 plantas por metro quadrado. A densidade de plantas por unidade de área também está em função do produto final desejado com o cultivo. Quando objetiva-se a produção de fibras, utilizamse populações maiores, e quando produção de sementes, utilizam-se populações menores (Gabiana, 2005). E este aumento na densidade de plantio pode afetar características da planta além do propiciar o aparecimento de doenças (Bassegio et al., 2012).

Perante Marques (2008) recomenda-se, no Brasil, o plantio da linhaça em ciclo curto, cerca de 150 dias. Estando a densidade de plantio da linhaça em 120 plantas por metro quadrado quando se objetiva a produção de fibras, no entanto, quando o objetivo é elevar a produção de sementes, recomenda-se a densidade de 90 plantas por metro quadrado.

Atualmente a agricultura nacional necessita adaptar-se as novidades circunstanciais e as complexidades de forma a manter competitividade, sendo assim, os produtores devem aperfeiçoar técnicas visando-se maior aproveitamento dos recursos produtivos disponíveis (Oliveira et al., 2012). Estudar a densidade de plantas é importante por se tratar de uma aplicação pratica na cultura que perante Silva et al. (2006), mais afetam o rendimento das culturas em geral, porém se tratando da cultura da linhaça esses estudos são muito escassos.

Perante o exposto o objetivo do atual trabalho é avaliar a influência das densidades populacionais de plantio da linhaça marrom (Linum usitatissimum L), visando aperfeiçoar as técnicas produtivas, analisando-se o comportamento fenométrico desta, tendo-se como variável os espaçamentos entre as plantas cultivadas em sistemas de linhas distanciadas a $0,45 \mathrm{~m}$, entre uma linha e outra. 


\section{MATERIAL E MÉTODOS}

Este trabalho foi desenvolvido na área experimental da Universidade Estadual do Oeste do Paraná - UNIOESTE, campus Cascavel-PR, que apresenta um solo classificado como latossolo vermelho distroférrico típico, possuindo precipitação média anual é de $1.640 \mathrm{~mm}$ e temperatura média de $19^{\circ} \mathrm{C}$, a região apresenta clima temperado mesotérmico e super úmido (IAPAR, 2011), e precipitação média mensal de $60 \mathrm{~mm}$, bem distribuídos ao longo de todos os meses do ano (Kaefer, 2007) e com localização geográfica $24^{\circ} 59^{\prime} 20,5^{\prime \prime}$ Sul, $53^{\circ} 26^{\prime} 58,7^{\prime \prime}$ Oeste.

O experimento foi conduzido de forma inteiramente casualizada partindo de linhas de cultivo, composta por oito sistemas de plantio com espaçamentos de 67, 84, 99, 117, 137, 154, 172 e 190 plantas $/ \mathrm{m}^{2}$ (Tabela 1), com seis repetições cada. Não foi realizado adubação ou tratos culturais no decorrer do experimento. A semeadura foi realizada a uma profundidade de $1 \mathrm{~cm}$ da superfície do solo, 20 dias após o plantio foi realizado o raleio, delimitando-se as distâncias entre plantas.

Tabela 1. Sistemas de plantio utilizados na área experimental da Unioeste, Cascavel - PR

\begin{tabular}{|c|c|c|c|c|c|c|c|c|}
\hline Irstin & $\$ 1$ & 5 & 53 & 54 & 5 & 56 & 57 & 8 \\
\hline F:m (m) & 67 & 84 & 99 & 117 & 137 & 154 & 172 & 15 \\
\hline
\end{tabular}

O experimento foi implantado no dia 06 de junho de 2013, sendo a colheita realizada aos 130 pós-semeadura, e após, foram avaliadas as seguintes características: altura de planta (AP) (com auxílio de uma fita métrica), número de capítulos por planta (NC), massa fresca (MFS) e massa seca (MSS) das sementes, massa fresca (MFP) e seca (MSP) da planta, diâmetro de caule (DC), e número de ramificações (NR) da planta. A massa seca foi determinada após a permanência das amostras em uma estufa a $65^{\circ} \mathrm{C}+-2^{\circ} \mathrm{C}$, no período de três dias, até que se atingiu o peso constante de massa seca das amostras.

Para verificar diferença estatística entre os grupos considerados realizou-se o teste de Tukey os resultados obtidos também foram submetidos à análise de regressão linear, adotou-se o nível de $1 \mathrm{a}$ 5\% de significância. Utilizou-se o pacote estatístico Assistat ${ }^{\circledR}$ versão 7.5 beta (Silva e Azevedo, 2002).

\section{RESULTADOS E DISCUSSÃO}

Observa-se na Tabela 2, que todas as análises realizadas, obtiveram regressão linear significativa $(\mathrm{P}<0,01)$, no sistema de plantio de densidades populacionais.

O sistema de semeadura em linha proporcionou resultados que diferem entre si através da aplicação da comparação de médias quando se utiliza o teste de Tukey. Quanto a Interferência da densidade sobre a altura da planta os sistemas de tratamento S1 e S2 diferiram significativamente dos tratamentos S4 e S8, e apesar de o tratamento S6 também apresentar diferença significativa destes últimos a altura da planta apresentou regressão linear com $p>0,99$, e teve a regressão quadrática não significativa, ou seja, uma tendência de quanto maior a densidade de cultivo da linhaça, nas densidades analisadas e cultivadas em sistema de linha, maior é a altura destas.

Diferentemente deste trabalho, Tomassoni et al. (2013) também estudaram o efeito do adensamento da linhaça (marrom e dourada) de 100, 150, 200 e 250 plantas $/ \mathrm{m}^{2}$, não relatando diferenças significativas com relação a altura entre estes sistemas de tratamento testados. Enquanto Gabiana (2005) observou efeitos negativos quando se aumenta a população de linhaça, contudo este utilizou densidades populacionais muito superiores às estudadas neste trabalho, sendo 238, 379, 583 e 769 plantas $\backslash \mathrm{m}^{2}$, resultando em alturas de $52.3,49.7,48.9$ e $47.5 \mathrm{~cm}$, respectivamente, sendo que neste trabalho utilizou-se 67 a 190 plantas $/ \mathrm{m}^{2}$ resultando em alturas de até $62,67 \mathrm{~cm}$, superior a encontrada por Gabiana (2005) e inferior a média encontrada por Tomassoni et al. (2013), que foi $67,5 \mathrm{~cm}$.

Deve-se levar em consideração que a colheita realizada por Tomassoni et al. (2013) foi realizada 140 dias após o plantio, enquanto o atual trabalho o tempo de cultivo foi de 130 dias, e também houve diferenças no período de cultivo de abril, no de Tomassoni, para junho, no atual. Desta torna-se necessário o desenvolvimento de um trabalho que englobe ambas as densidades de plantio buscando-se um 
ajuste fino da melhor densidade de plantio objetivando-se ganho de altura.

Tabela 2. Efeito da densidade de plantio de linhaça marrom.

\begin{tabular}{|c|c|c|c|c|c|c|c|c|}
\hline Trat. & $\begin{array}{c}\mathbf{A P} \\
(\boldsymbol{\sigma})\end{array}$ & ( & NC & NR & $\begin{array}{c}\text { MFP } \\
(0)\end{array}$ & $\begin{array}{l}\text { MLP } \\
f(\Rightarrow)\end{array}$ & $\begin{array}{c}\text { Mrs } \\
(\rightarrow)\end{array}$ & $\begin{array}{l}\text { MLS } \\
\Leftrightarrow(\Leftrightarrow)\end{array}$ \\
\hline S1 & 51,7 hed & $15,33 \mathrm{e}$ & $11,17 \mathrm{e}$ & $1,0=$ & $1,7 \sqrt{d}$ & $1,25 \mathrm{e}$ & $\bar{l}, \mathbf{B} \mathbf{c}$ & 0,94 \\
\hline 52 & $51,0 \mathrm{dd}$ & $24,000 \mathrm{~d}$ & 18,83d & 2, She & 2260 & 1,4Bde & $15 \mathrm{lbc}$ & $122 x$ \\
\hline 포 & 57, $3 \mathrm{de}$ & $303 \overline{36 x}$ & $2733 x$ & $1, \overline{k e d}$ & 3,2106 & 1,7 ed & $20.6 x$ & $16 \mathrm{sk}$ \\
\hline S4 & $61,67 a$ & 39,83 a & 34,000 & $2 \mathrm{s36}$ & $5,17 a$ & 279 & 2506 & $2,02 \pi$ \\
\hline 포 & $5933-6$ & 4675 & 340 & 3,6 & $3, \mathrm{Ted}$ & $258-6$ & 2376 & 2,2 \\
\hline$\underline{55}$ & $49,0 \mathrm{~d}$ & $27,17 \mathrm{ded}$ & $22,3 \times d$ & $2 \pi$ & 26 ed & $162 d$ & $15 \mathrm{lbc}$ & $132 x$ \\
\hline$\overline{57}$ & $77,5 \mathrm{de}$ & $8334 d$ & 245 & $167 d$ & 3,766 & 2,2lbc & 167/be & $1,61 \mathrm{skx}$ \\
\hline$\underline{5}$ & $62,67 a$ & 34,536 & 39,6 & 2,67 & 5,33 & 283 & 297 & $2,03 \pi$ \\
\hline$\overline{\text { RIE }}$ & $13,3 * *$ & $87,58^{* *}$ & $240,68=7$ & $2294 * 3$ & $119,7 \times$ & $99,3 * 6$ & $16,7 * 7$ & $18,8 * t$ \\
\hline 10. & $0,45 \mathrm{~m}$ & $33,63 * *$ & $43,0^{*} * t$ & $49,60^{* * *}$ & $5,18^{*}$ & $11, k^{* * *}$ & 0,0 , & $9,14 * t$ \\
\hline CV56 & $r_{3}$ & 10,04 & $3, \mathbf{B}+$ & $\mathbf{3}, \mathbf{B 3}$ & 14,47 & 12,87 & 30,20 & 24,15 \\
\hline 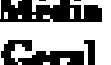 & 56,27 & 29,40 & 26,54 & 2,35 & 3,50 & 2,07 & 1,9 & $1,6]$ \\
\hline
\end{tabular}

Médias seguidas pela mesma letra na coluna não diferem estatisticamente entre si pelo teste de Tukey $(p<0,05)$. $\left({ }^{* *}\right)=$ Significativo a $1 \%$ de probabilidade, $\left({ }^{*}\right)=$ significativo a $5 \%$ de probabilidade, $(n s)=$ não significativo. CV\%: Coeficiente de Variação. R.L.: Regressão Linear. R.Q.: Regressão Quadrática. AP: Altura da Planta. DC: Diâmetro do Caule. NC: Numero de Capsulas. NR: Numero de Ramificações. MFP: Massa Fresca da Planta. MSP: Massa Seca da Planta. MFS: Massa Fresca das Sementes. MSS: Massa Seca das Sementes.

A análise do diâmetro do caule (DC) apresentou como melhor resultado o adensamento de 117 plantas $/ \mathrm{m}^{2}$, quando se almeja um ganho de espessura, apresentando $39,83 \mathrm{~mm}$ de diâmetro, 10,43 cm superior a média, sendo que os demais sistemas de tratamento superiores ou inferiores a este adensamento apresentaram resultados menos expressivos, não se diferenciando significativamente $(p>0,05)$ apenas nos adensamentos 137 e 190 plantas $/ \mathrm{m}^{2}$.

A análise do número de capsulas apesentou como melhor resultado o sistema de plantio S8 (190 plantas $/ \mathrm{m}^{2}$ ), diferindo-se significativamente ao nível de $5 \%$ em relação as médias dos outros sistemas, culminando no resultado de maior adensamento refere-se a maior produção em número de capsulas. No adensamento máximo deste trabalho, que foi 190 plantas $/ \mathrm{m}^{2}$ alcançou-se a média quantitativa de 39,66 capsulas por planta, enquanto Gabiana (2005), em seu menor adensamento que foi 238 plantas/ $\mathrm{m}^{2}$, o mais próximo ao atual trabalho, relata ter obtido apenas 24,30 capsulas por planta, uma quantia inferior à encontrada no atual trabalho.

Quanto ao número de ramificações o sistema de plantio S5 apesentou a maior quantidade de ramificações diferindo-se significativamente ao nível de 5\% quando aplicado o teste de Tukey das outas densidades de plantio analisadas. Já com relação a massa seca da semente não houve diferença estatística, quando aplicado o teste de Tukey entre os adensamentos S3, S4, S5, S7 e S8 apesentando produções muito semelhantes. Neste trabalho encontraram-se resultados que diferiram dos encontrados por Lisson e Mendham (2000) que verificaram ocorrer uma elevação do rendimento da cultura com a elevação da densidade populacional. Contudo, os sistema de plantio S1 e S2 obtiveram os menores rendimentos em semente corroborando com o trabalho de Lisson e Mendham (2000).

Apesar de não ser uma correlação diretamente proporcional, como o relatado por Ali et al., (2009), a produtividade de sementes pode ser relacionada com número de cápsula e peso das sementes.

Levando-se em consideração o produto de desejo da linhaça, que é a semente, geralmente, não pode-se obter um melhor adensamento ou sistema de plantio levando-se em consideração a MFS e a MSS. Uma forma de maximizar ou ampliar estas diferenças seria elevar o tempo de cultivo que foi apenas de 130 dias sendo que na literatura encontra-se média de 150. 


\section{CONCLUSÃO}

Quando pouco adensado, inferior a 99 plantas $/ \mathrm{m}^{2}$, o cultivo de linhaça tende a diminuir sua produtividade, quando cultivado em sistema de linhas espaçadas a $0,45 \mathrm{~m}$, apresentando o melhor rendimento em grãos, na maioria dos sistemas analisados, quando utilizadas as densidades de 100 a 190 plantas $/ \mathrm{m}^{2}$, não podendo diferenciar o melhor estatisticamente.

\section{REFERÊNCIAS}

ALI, M. A., NAWAB, N. N., ABBAS, A., ZULKIFFAL, M., \& SAJJAD, M. Evaluation of selection criteria in Cicer arietinum L. using correlation coefficients and path analysis. Australian Journal of Crop Science, v. 3, n. 2, 2009. p.65-70.

ALVES, D.L.; SILVA, C.R. Fitohormônios: abordagem natural da terapia hormonal. São Paulo: Editora Atheneu, 2003.

ARGENTA, G.S; FERREIRA, P.R.; SANGOI, L. Arranjo de plantas em milho: análise do estado-da-arte. Ciência Rural, v.31, n.6, 2001. p.1075- 1084.

BASSEGIO, D.; SANTOS, R.F.; NOGUEIRA, C.E.C.; CATTÂNEO, A.J.; ROSSETTO, C. Manejo da irrigação na cultura da linhaça. Acta Iguazu, Cascavel, v.1, n.3, 2012. p. 98-107.

BOMBO, A.J. Obtenção e caracterização nutricional de snacks de milho (Zeamays L.) e linhaça (Linum usitatissimun L.). Dissertação Mestrado, Faculdade de Saúde Pública, USP. São Paulo-SP. 2006. 97p.

GABIANA, C. The response of linseed (Linum usitatissimum L) to irrigation, nitrogen and plant population. Dissertação (Master of Applied Science), Lincoln University. Jefferson City, 2005.

IAPAR - Instituto Agronômico do Paraná. Médias históricas em estações do IAPAR. 2011. Disponível em: $<$ http://www.iapar.br/arquivos/Image/monitoramento/Medias H istoricas/Cascavel.html>. Acesso em: 12 abr. 2011.

KAEFER, D.B. Diagnóstico local do município de Cascavel. Universidade Federal do Paraná Setor de Ciências da Saúde. 2007.

KOUBA M. Effect of dietary omega-3 fatty acids on meat quality of pigs and poultry M.C. Teale (Ed.), Omega 3 Fatty Acid Research, Nova Publishers, New York. 2006. p. 225-239.

LISSON, S. N.; MENDHAM, N. J. Agronomic studies of flax (Limon usitatissimwn L.) in a south-eastern Australia. Australian journal of Experimental Agriculture, v.40, 2000. p.1101-1112.

MARQUES, A. C. Propriedades funcionais da linhaça (Linum usitatissimum L.) em diferentes condições de preparo e de uso em alimentos. 2008. Dissertação (Mestrado em Ciência e Tecnologia de Alimentos) - Centro de Ciências Rurais, Universidade de Federal de Santa Maria, Santa Maria, 2008. p.115.

MARQUES, A.C.; HAUTRIVE, T.P.; MOURA, G.B.; COLLEGARO, M.G.K.; HECKTHEUER, L.H.R. Efeito da linhaça (Linum usitatissimum L.) sob diferentes formas de preparo na resposta biológica em ratos. Revista Nutrição, vol.24, n.1, Campinas Jan/Fev, 2011.

MORRIS, D.H.; VAISEY-GENSER, M. Flaxseed. Encyclopedia of Food Sciences and Nutrition, v.10, n.2, 2003. p.2525-2531.

OLIVEIRA, M.R. de; SANTO, R.F.; ROSA, H.A.; WERNER, O.; VIEIRA, M.D.; DELAI, J.M. Fertirrigação da cultura de linhaça Linum usitatissimum. Revista Brasileira de Energias Renováveis, v.1, p.22-32. 2012. 
OOMAH, B.D. Flaxseed as a functional food source. J Sci Food Agric. v. 81, 2001. p. 889- 894.

RABETAFIKA, N.H.; REMOORTEL, V.V.; DANTHINE, S. Flaxseed proteins: food uses and health benefits. International Journal of Food Science and Technology, n.46, 2011. p.221-228.

SCHULZ, V.; HÄNSEL, R.; TYLER, V.E. Fitoterapia Racional: um guia de fitoterapia para as ciências da saúde. 4 ed., São Paulo: Manole, 2001.

SILVA, P.R.F. SANGOI, L.; STRIEDER, M.L.; ARGENTA, G. Importância do arranjo de plantas na definição da produtividade do milho. Porto Alegre: Departamento de Plantas de Lavoura da UFRGS: Evangraf, 2006. p.64.

SOARES, L.L; PACHECO, J.T; BRITO, C.M de; TROINA, A. de A.; BOAVENTURA, G.T.; GUZMÁNSILVA, M.A. Avaliação dos efeitos da semente de linhaça quando utilizada como fonte de proteína nas fases de crescimento e manutenção em ratos. Rev. Nutr., v.22, n.4, 2009. p.483-491.

TOMASSONI, F.; SANTOS, R.F.; BASSEGIO, D.; SECCO, D.; SANTOS, F.S.; CREMONEZ, P.A. Diferentes densidades de plantio na cultura da linhaça dourada. Acta Iguazu, Cascavel, v.2, n.3, 2013. p. 8-14.

TRUCOM, C. A importância da linhaça na saúde. São Paulo: Alaúde, 2006, p.152.

VIEIRA, M. D.; SANTOS, R.F.; ROSA, H.A.; WERNER, O.V.; DELAI, J.M.; OLIVEIRA, M.R. Potássio (K) no cultivo da linhaça Linum usitatissimum. Revista Brasileira de Energias Renováveis, v.1, 2012. p.62-69. 